J. Lake Sci. (湖泊科学) , 2020, 32(3): 745-753

DOI 10. 18307/2020. 0314

(c) 2020 by Journal of Lake Sciences

\title{
洞庭湖洲滩土壤种子库对土壤水分变化的响应
}

\author{
陈明珠 ${ }^{1}$, 靳 朝 $^{2}$, 雷光春 ${ }^{1}$, 阳 俭 ${ }^{3}$, 雷 霆 ${ }^{1 * *}$ \\ (1: 北京林业大学生态与自然保护学院,北京 100083) \\ ( 2 : 河南省出入境检验检疫局,郑州 450003) \\ (3: 湖南省西洞庭湖国家级自然保护区管理局,常德 415000)
}

\begin{abstract}
摘 要: 由于三峡大坝及上游水库群的运行, 长江中下游水域水文节律随之发生了改变, 导致洞庭湖枯水期提前, 进而影 响洞庭湖洲滩植被及其土壤种子库的分布格局. 本研究在洞庭湖 4 个自然保护区内选取共 11 个典型洲滩湿地,沿由水到 陆方向根据植被类型将洲滩分为泥沙洲滩、泥沙一湖草洲滩过渡带、湖草洲滩、湖草一南荻洲滩过渡带、南荻洲滩 5 种洲滩 类型. 通过样带一样方法调查和采样, 并结合湿润和水淹两种条件下的土壤种子库萌发实验, 分析了土壤水分变化对洲滩 种子库萌发特征的影响及土壤种子库与地表植被的关系. 结果显示: (1)土壤含水量沿水到陆方向由泥沙洲滩向南荻洲滩 递减; (2)不同类型洲滩土壤种子库密度没有显著差异; (3)温室萌发实验中,水淹条件下土壤种子库物种丰富度和种子库 密度显著降低, 东洞庭湖自然保护区土壤种子库物种丰富度和种子库密度较高; (4)地表植被物种丰富度高于土壤种子 库, 泥沙洲滩土壤种子库与地表植被物种组成的 Jaccard 相似性指数最低. 此外, 蔀草 (Phalaris arundinacea)、芦苇( Phragmites communis)、南荻 (Miscanthus sacchariflorus) 等只在地表植被中存在, 而陌上菜 (Lindernia procumbens)、通泉草 (Mazus japonicus $)$ 等只在种子库中存在. 结果表明, 在进行湿地植被恢复时, 不能仅依靠种子库移植技术, 还要考虑湖区季节性的 水位变化以及个别物种的特异性,配合有针对性的水文调控机制及相关的人工措施恢复其原有植被.
\end{abstract}

关键词: 土壤种子库;物种多样性; 地表植被;洞庭湖;洲滩湿地;土壤含水量

\section{The response of soil seed bank diversity to soil moisture change in Lake Dongting *}

\author{
CHEN Mingzhu' ${ }^{1}$, JIN $_{\text {Zhao }}{ }^{2}$, LEI Guangchun ${ }^{1}$, YANG Jian $^{3}$ \& LEI Ting ${ }^{1 * *}$ \\ (1: School of Ecology and Nature Conservation, Beijing Forestry University, Beijing 100083, P.R.China) \\ (2: Henan Entry-Exit Inspection and Quarantine Bureau, Zhengzhou 450003, P.R.China) \\ (3: West Dongting Lake National Nature Reserve, Hunan Province, Yueyang 415923, P.R. China)
}

Abstract: Due to the operation of the Three Gorges Dam and upstream reservoir groups, the hydrological rhythm of the middle and
lower reaches of the Yangtze River has changed subsequently, which resulted in habitat changes in Lake Dongting. However, these
habitat changes not only affect the distribution of wetland vegetation but also influence the soil seed bank in Lake Dongting. To ex-
plore the influence of soil moisture variation on wetland soil seed bank germination and the relationship between soil seed bank and
ground vegetation, 11 typical sites were set in field investigation, which were classified into 5 kinds of floodplains ( silt floodplain,
silt and grass transition zone, grass floodplain, grass and reed transition zone, reed floodplain). In addition, soil seed bank germi-
nation experiment was carried out under two types of treatment ( moisture and flooded conditions). The results revealed that soil
moisture decreased from silt floodplain to the reed floodplain. The density of soil seed bank of 5 floodplains had no significant differ-
ence. In the germination experiment, the species richness and soil seed bank density in moisture group was significantly higher than
in the water flooded group, besides, the species richness and seed bank density in soil seed bank of East Dongting Lake Nature Re-
serve were significantly higher. Moreover, the species richness of ground vegetation was higher than soil seed bank, and the Jaccard
similarity index of soil seed bank and surface vegetation in silt floodplain was the lowest. Phalaris arundinacea, Phragmites commu-
nis and Miscanthus sacchariflorus only existed in ground vegetation, while Lindernia procumbens and Mazus japonicus only existed in

* 2019-08-13 收稿; 2019-11-19 收修改稿.

国家重点研发计划项目 (2018YFC0507200) 资助.

** 通信作者;E-mail: leiting@bjfu.edu.cn. 
soil seed bank. In conclusion, it is not possible to rely solely on the seed bank transplantation technology to restore vegetation, the seasonal water level change and the specificity of some species should also be put into consideration. Meanwhile, matching targeted hydrological regulation mechanisms and related artificial measures can help to rehabilitate successfully.

Keywords: Soil seed bank; plant diversity; ground vegetation; Lake Dongting; floodplain; soil moisture

湿地是单位面积生态服务价值最高的生境类型 ${ }^{[1]}$,工业发展、城市化、水利工程等导致湿地生态系统面 临多种威胁 ${ }^{[2]}$. 利用种子库技术修复受损湿地是当前湿地研究的热点之一 ${ }^{[3]}$. 研究表明, 建设和运用大型水 利水电工程, 会对下游湿地生态系统的水文节律造成影响 ${ }^{[4]}$. 植物群落的生长发育和繁殖等过程都与水位 波动有着密切的关系 ${ }^{[5]}$, 土壤含水量也是影响湿地植被特征的重要因素 ${ }^{[6]}$. 种子库作为地表植被更新的重 要来源, 对植物群落受到的破坏能够起到缓冲作用, 减少植物种群灭绝的几率 ${ }^{[7-8]}$. 湿地土壤种子库的大小 和组成受水文因子、土壤条件 ${ }^{[9-10]}$ 、湿地类型 ${ }^{[11]}$ 和地表植被 ${ }^{[12]}$ 等因素的影响, 研究种子库的组成能够了解 退化湿地生态系统的物种资源储备 ${ }^{[13]}$, 还能用于湿地生态系统质量评估、植被演替趋势预测以及植被恢复 物种选择等方面的工作 ${ }^{[14-15]}$.

土壤种子库受地表植被结构变化及生物学节律影响, 其物种组成也会反映地表植物群落的演替趋 势 ${ }^{[16]}$. 沼泽湿地及以无性繁殖为主的植被类型中, 种子库与地表植被相似性较低 ${ }^{[17]}$, 潮汐淡水湿地及以一 年生为主的植被类型中其相似性较高 ${ }^{[18]}$. 侯志勇等研究了洞庭湖特定区域内曧草、苔草和荻群落地表植被 与土壤种子库的相关性 ${ }^{[19]}$, Cui 等也在太湖研究了 4 种植物群落地表植被与土壤种子库的相关性 ${ }^{[20]}$. 本次 研究立足于洞庭湖当前所面临的生态危机, 分别在东洞庭湖、横岭湖、南洞庭湖和西洞庭湖的典型洲滩湿地 上采集土壤样品, 研究水分胁迫对洲滩湿地种子库萌发特征的影响, 分析泥沙洲滩、泥沙一湖草洲滩、湖草洲 滩、湖草一南荻洲滩、南荻洲滩 5 类洲滩地土壤种子库与地表植被的相似性, 以期为水文情势变化后洲滩湿 地植被的修复策略提供参考.

\section{1 研究区域与研究方法}

\section{1 研究区域概况}

洞庭湖位于长江中游荆江南岸, 地处湖南省北部以及湖北省南部, 属亚热带湿润季风气候, 年平均温度 $16.4 \sim 17.0^{\circ} \mathrm{C}$, 年平均降水量 $1200 \sim 1550 \mathrm{~mm}$, 年平均湿度 $80 \%$, 全年无霜期为 $260 \sim 280 \mathrm{~d}^{[21]}$. 洞庭湖汇集了 湘、资、沅、澧四水及长江水资源, 再由岳阳城陵矶注人长江, 是典型的过水性吞吐型湖泊, 多年平均水位24 $31 \mathrm{~m}^{[22]}$. 湖区已建立东洞庭湖、西洞庭湖国家级自然保护区, 以及横岭湖、南洞庭湖省级自然保护区. 其洲 滩湿地沿水岸向内陆依次为泥沙洲滩、湖草洲滩、南荻洲滩及鸡婆柳一旱柳洲滩 4 种主要类型 ${ }^{[10]}$. 本研究选 取的洞庭湖区域主要包括前 3 种洲滩类型, 并在研究过程中将洲滩之间的过渡区域划分为新的类型, 即泥 沙洲滩、泥沙一湖草洲滩过渡带、湖草洲滩、湖草一南荻洲滩过渡带、南荻洲滩 ${ }^{[23]}$.

\section{2 植被调查及土壤种子库取样}

2013 年 1 月, 在洞庭湖 4 个自然保护区内选取共 11 处典型洲滩湿地作为样地, 其中东洞庭湖 5 处, 横 岭湖 1 处, 南洞庭湖 3 处, 西洞庭湖 2 处 (图 1 , 表 1 ).

洞庭湖水位每年自 10 月逐渐下降, 至 $12-1$ 月达到最低值, 来年 4 月开始水位缓慢上 升 $^{[24]}$. 在此水位 变化过程中, 洲滩湿地面积逐渐增加, 在 12 月到 1 月之间达到最大值, 后缓慢缩小. 我们选择在洲滩面积接 近最大值的时期, 在每个样地内设置 3 条由近水裸滩至南荻群落、垂直于水陆交界线的重复样带, 样带长度 $600 \sim 1200 \mathrm{~m}$, 间距为 200 300 m. 采取用空间代替时间的方法设计样品采集方案, 每条样带不同部分均包含 了洲滩湿地植物从萌发、生长到成熟的各个阶段, 采集的混合土壤样品基本包含了各种状态且具有活性的 种子.

沿样带布设样方数量为泥沙洲滩 1 个、泥沙一湖草过渡带 1 个、湖草洲滩 2 个、湖草一南荻过渡带 1 个、 南荻洲滩 1 个, 样方间距为 $100 \sim 200 \mathrm{~m}$ (图 1), 样方大小为 $1 \mathrm{~m} \times 1 \mathrm{~m}$. 调查每个样方内的维管植物种数及个 体数, 使用 WET- 2 土壤三参数仪测量每个样方土壤含水量. 使用工兵铲铲取每个样方中心位置表层 $10 \mathrm{~cm} \times$ $10 \mathrm{~cm} \times 10 \mathrm{~cm}$ 的土样装人塑封袋密封、标记,带回实验室置于 $5^{\circ} \mathrm{C}$ 条件下冷藏. 


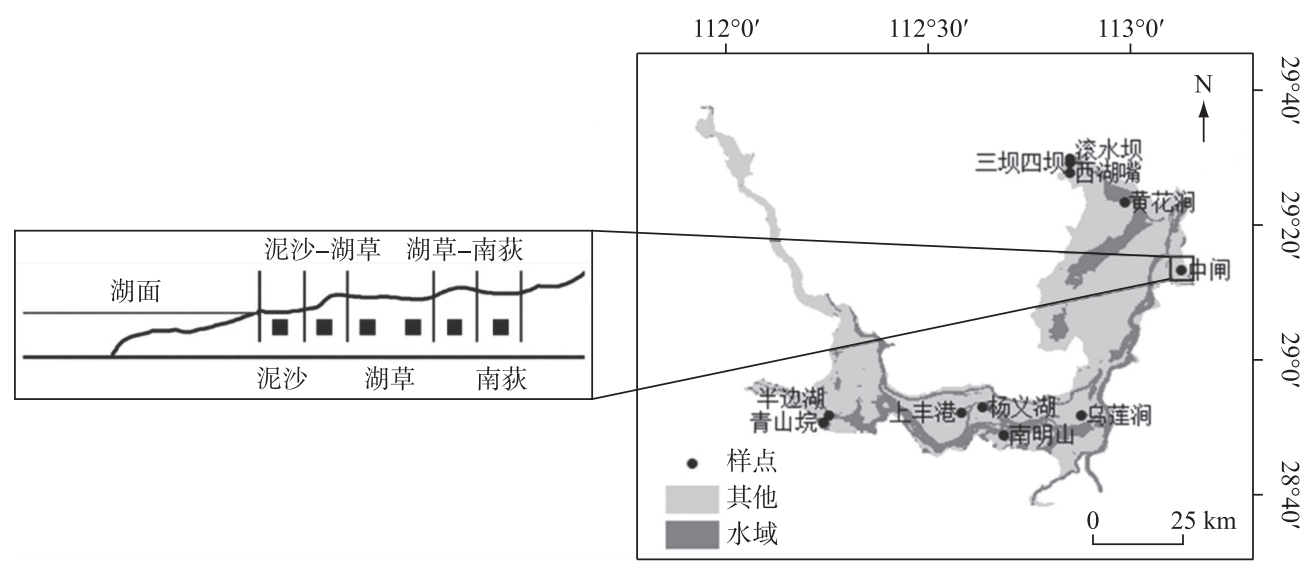

图 1 样点分布及样方设置( “表”示样方)

Fig.1 Distribution of sampling sites and quadrat setting (“口” represents quadrat)

\section{3 种子萌发实验}

1.3.1 预处理 采用萌发法,于 4 月在西洞庭湖国家级自 然保护区管理局蒋家嘴分局 $\left(28^{\circ} 49^{\prime} 35^{\prime \prime} \mathrm{N}, 112^{\circ} 12^{\prime} 11^{\prime \prime} \mathrm{E}\right)$ 的温室内进行种子库萌发实验, 温室内保持通风. 将土 样根据每个样带不同洲滩类型混合均匀, 过 $4 \mathrm{~mm}$ 笁网, 除去石块并分拣出土壤中的植物根状茎. 使用四分法将 土样平均分成 4 份, 根据不同处理和重复放置于相应萌 发盒内. 萌发盒体积为 $15 \mathrm{~cm} \times 10 \mathrm{~cm} \times 5 \mathrm{~cm}$, 底部钻 8 个孔用于透水. 萌发盒填充物分为 3 层, 最下层铺垫滤 纸防止样品和基质掉落, 中层为不含有机质的蛭石作为 萌发基质, 上层放置厚度为 $2 \mathrm{~cm}$ 的土壤样品 ${ }^{[25]}$. 已有研 究表明, 萌发实验中仅有表层 $1 \sim 2 \mathrm{~cm}$ 的种子会从土壤 种子库中萌发 ${ }^{[26]}$, 而蛭石基质的作用为保持水分和为幼 苗根系生长提供空间. 部分植物可依靠根状茎进行营养 繁殖, 实验中, 另将土壤中分拣出的根状茎单独放置于 相同规格的萌发盒内进行萌发.

1.3.2 温室实验设置实验中设置 2 种处理, 每种处理下 3 个重复, 每个重复设置 2 个平行样本以降低系统 误差: (1) 水淹处理,萌发盒置于大小约 $60 \mathrm{~cm} \times 45 \mathrm{~cm} \times 45 \mathrm{~cm}$ 的水箱内, 水面没过土样上表面约 $15 \mathrm{~cm}$; (2) 湿润处理, 样本置于大小约 $60 \mathrm{~cm} \times 45 \mathrm{~cm} \times 5 \mathrm{~cm}$ 的托盘内, 水面高度约 $1 \sim 3 \mathrm{~cm}$; 在温室四角和中间位置 放置 5 个托盘, 放置无土壤样品的萌发盒作为空白组, 用于排除温室周边植物种子扩散影响. 萌发过程中, 湿润处理组和空白组每天加水保持土样湿润,水淹处理组始终保持淹没高度达到 $15 \mathrm{~cm}$.

1.3.3 数据获取 从有种子萌发开始, 每星期记录 1 次萌发物种的种类及数量. 已鉴定和记录的幼苗当即剔 除, 避免其产生第 2 代种子落人种子库; 暂时无法鉴定的幼苗将移栽并培养至可鉴定为止. 至不再有新种子 萌发, 继续观察 1 个月后结束实验.

\section{4 数据处理}

1.4.1 种子密度计算 记录各萌发盒内萌发物种数及其幼苗总数, 根据土壤取样面积换算为每平方米种子数 量作为种子密度指标, 本研究中土壤样本采样面积为 $0.01 \mathrm{~m}^{2}$, 每份土样分为 2 个不同处理和 2 个平行样本, 因此每个样本的种子密度为萌发株数 $\times 400$, 单位为粒 $/ \mathrm{m}^{2}$.

1.4.2 Margalef 指数 用 Margalef 指数 $(R)$ 分析种子库和地表植物物种丰富度: 


$$
R=\frac{S-1}{\ln N}
$$

式中, $S$ 表示植被群落中物种数目, $N$ 表示植被群落中全部物种个体总数.

1.4.3 Jaccard 指数 采用 Jaccard 指数 $\left(C_{J}\right)$ 相似性系数计算种子库与地表植被物种相似程度 ${ }^{[11]}$ :

$$
C_{J}=\frac{j}{a+b-j}
$$

式中, $j$ 为种子库及其对应植物群落共有种, $a$ 和 $b$ 分别为物种数.

\section{5 数据分析}

利用三因素方差分析( Three-way ANOVA) 分析不同洲滩类型、自然保护区和水位处理条件下种子库萌 发的密度和物种丰富度的差异,利用单因素方差分析 (One-way ANOVA) 对 5 类洲滩地土壤种子库 Margalef 指数、土壤种子库与地表植被物种组成相似性以及不同水位条件下种子萌发相似性差异进行比较. 若存在 显著性差异则采用 LSD 检验进行多重比较. 采用 Pearson 相关性分析法分析土壤含水量与种子库大小的相 关性, 显著度水平为 0.05. 采用统计软件 SPSS 22.0 (SPSS Inc., Chicago, IL, USA) 和 Excel 2003 进行数据处 理,采用 Sigma plot 12.5 软件 (2011, Systat Software, Inc., USA) 进行作图.

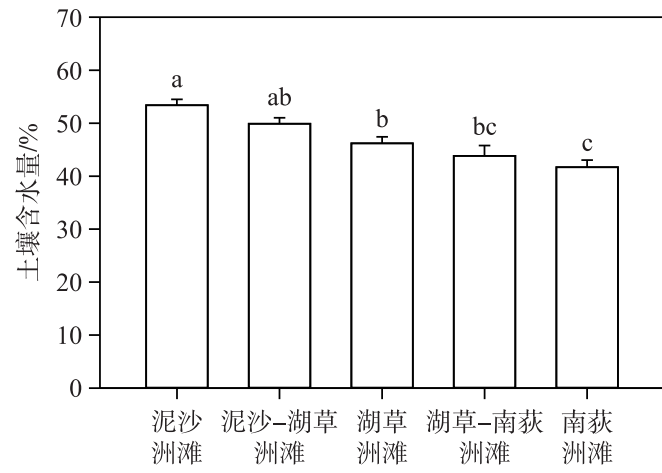

图 2 不同类型洲滩土壤含水量

（标有不同小写字母表示差异显著, $P<0.05$ )

Fig. 2 Soil moisture of different kinds of floodplains

\section{2 结果与分析}

\section{1 各洲滩土壤含水量差异}

不同洲滩土壤含水量存在显著差异 $(P<0.05)$. 泥 沙洲滩距离水面最近, 土壤含水量最高, 为 $53.4 \%$; 而 南荻洲滩远离水面, 土壤含水量最低, 为 $41.7 \%$. 沿由 水到陆方向, 土壤含水量为泥沙洲滩 $>$ 湖草洲滩 $>$ 南 荻洲滩( 图 2).

\section{2 洲滩土壤种子库萌发特征}

洞庭湖各类型洲滩土壤种子库密度和物种丰富度 均无显著差异 $(P>0.05)$. 不同自然保护区和水分处理 条件下, 土壤种子库萌发的密度和物种丰富度差异显 著 $(P<0.05)$. 洲滩类型、保护区、水分条件 3 种因素对 土壤种子库萌发的种子库密度和物种丰富度均没有显 著交互作用 $(P>0.05)$. 洞庭湖 4 个保护区间洲滩土壤 种子库密度和物种丰富度均差异显著 $(P=0.039 、 0.018$; 附录 I ). 其中, 东洞庭湖种子库密度最高, 南洞庭湖 最低( 图 3a), 洲滩种子库萌发的物种丰富度呈现同样的规律( 图 3b).
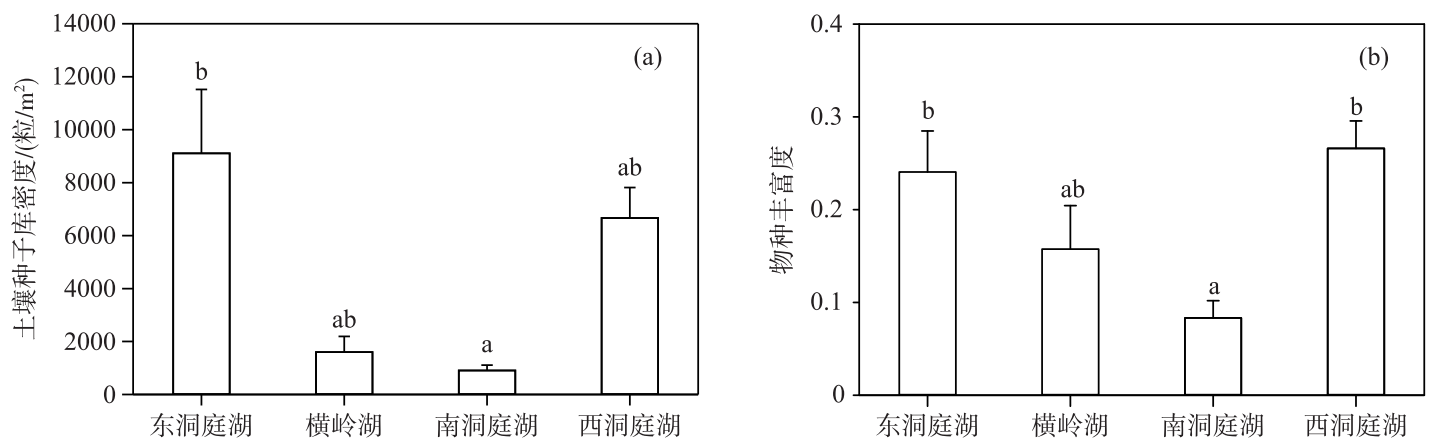

图 3 洞庭湖 4 个保护区土壤种子库密度 (a) 和丰富度 (b)

(标有不同小写字母表示差异显著, $P<0.05$ )

Fig.3 Soil seed bank density (a) and species richness ( b) of four nature reserves of Lake Dongting 
湿润条件下, 萌发的种子库密度显著高于淹水条件下的种子库密度 $(P<0.01)$. 湿润组物种丰富度显著 高于水淹组物种丰富度 $(P<0.001)$. 水淹条件下土壤种子库萌发物种数为 11 种, 其中一、二年生草本 5 种, 多年生草本 6 种,包括仅在水淹条件下萌发的金鱼藻 (Ceratophyllum demersum) 、苦草(Vallisneria natans) 和 菹草 (Potamogeton crispus).

\section{3 地表植被与土壤种子库的关系}

2.3.1 物种丰富度 不同洲滩地表植被物种丰富度差异显著 $(P<0.05)$, 且由水到陆方向, 物种丰富度逐渐增 大, 泥沙洲滩物种丰富度最小, 南荻洲滩物种丰富度最大 ${ }^{[23]}$. 地表植被物种丰富度显著高于土壤种子库 $(P<$ $0.05)$, 各类型洲滩土壤种子库萌发的物种丰富度没有显著差异 $(P>0.05$; 图 4). 调查样地内地表植物共 36 种, 湿润条件下种子库萌发物种数 32 种, 其中一、年生草本 23 种, 多年生草本 9 种.

2.3.2 物种相似性 不同洲滩类型土壤种子库与地表植被物种组成相似性均小于 0.2 , 且存在显著差异 $(P<$ 0.05 ; 图 5). 其中, 泥沙洲滩物种相似性显著低于湖草一南荻过渡带和南荻洲滩地 $(P<0.05)$, 而后 4 种洲滩 物种相似性差异不显著 $(P>0.05)$.

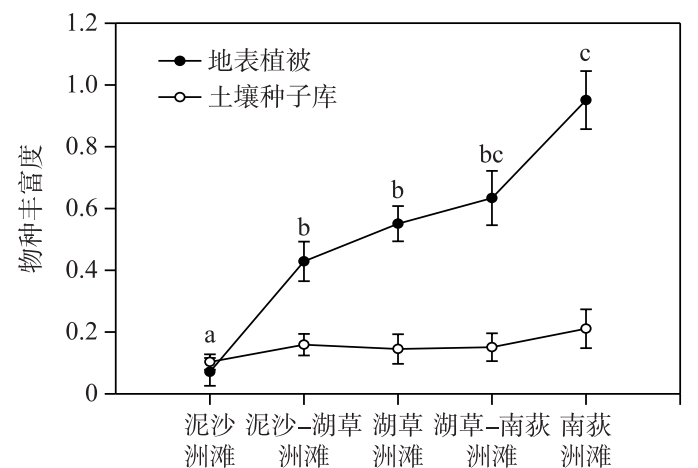

图 4 各类型洲滩下地表植物群落和 种子库物种丰富度 (标有不同小写 字母表示差异显著, $P<0.05)$

Fig.4 The species richness of different communities and seed banks of different kinds of floodplains

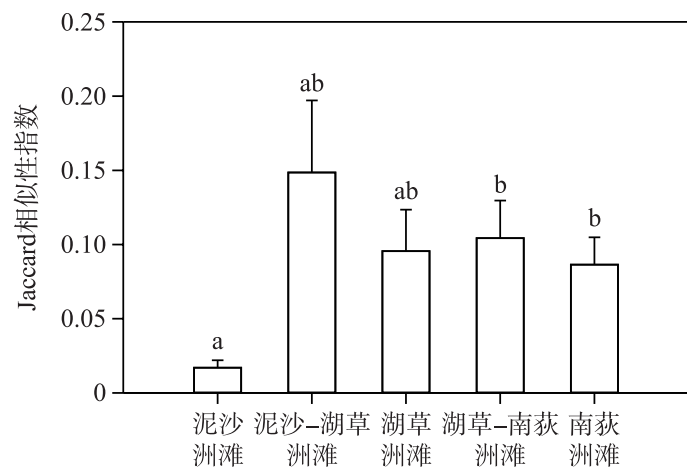

图 5 各类型洲滩下土壤种子库与洲滩 地表植被物种组成的 Jaccard 相似性指数 (标有不同小写字母表示差异显著, $P<0.05$ )

Fig. 5 The values of Jaccard index between seed banks and communities of different kinds of floodplains

2.3.3 优势种组成 调查区域内地表植被主要优势种包括蓼子草( Polygonum criopolitanum)、碎米荠 ( Cardamine hirsute) 等一年生草本植物, 以及刚毛荣荠 (Eleocharis valleculosa)、苔草 (Carex sp.)、曧草 (Phalaris arundinacea)、芦苇(Phragmites communis)、南荻 (Miscanthus sacchariflorus)、萎蒿( Artemisia selengensis) 等多年 生草本植物. 其中泥沙洲滩上长有大量苶子草, 面积最大的湖草洲滩则以苔草为主, 而南荻洲滩又以南荻占 优. 种子库中主要优势种包括陌上菜 (Lindernia procumbens)、石胡荌 (Centipeda minima) 、通泉草 (Mazus japonicus $) 、$ 苶子草等一年生草本植物以及刚毛芓荠、苔草等多年生草本植物. 其中曧草、芦苇、南荻只在地表 植被中存在, 而陌上菜、石胡荌、通泉草只在种子库中存在, 其余共有种的重要值均存在较大差异 $(P<0.05$; 图 6).

\section{3 讨论}

洞庭湖 4 个保护区中, 东洞庭湖国家级自然保护区种子库密度和物种丰富度明显高于南洞庭湖自然保 护区, 这可能与保护区湿地保护级别差异及水文和地貌特征的异质性有关. 洲滩湿地土壤含水量存在较为 明显的梯度分布, 而种子库密度从临近水体到内陆的南荻群落沿高程梯度没有显著差异. 而侯志勇等的研 究表明, 洞庭湖高水位区的土壤种子库密度大于低水位区, 高水位区的一些植物种在洪水来临前完成生活 史, 种子进人种子库 ${ }^{[19]}$. Greulich 等研究了种子库组成与水文和植被类型的关系, 发现在较大的洪水梯度 


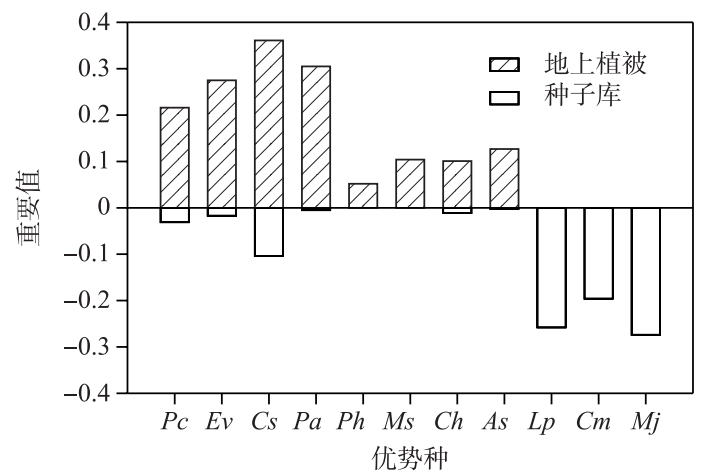

图 6 地上植被及种子库主要优势种重要值 $(P c$ : 苶子草; $E v$ : 刚毛荣荠; $C s$ : 苔草;

$P a$ : 翮草; $P h$ :芦苇; $M s$ : 南荻; $C h:$ 碎米荠; $A s$ : 萎蒿; $L p$ : 陌上菜; $C m$ : 石胡荽; $M j$ : 通泉草)

Fig.6 Importance value of the major dominant species in vegetation and seed banks
上,物种组成显著不同,但种子密度没有差异 ${ }^{[27]}$. 土 壤种子库的组成和分布与种子扩散能力 ${ }^{[28]}$ 、水文和 植被、生境条件等因子密切相关 ${ }^{[29]}$. 水文条件影响 洲滩植被的分布格局 ${ }^{[30]}$, 不同植物生产种子的能力 不同, 种子的性状也有差异, 种子性状一定程度决定 了种子的扩散能力 ${ }^{[31]}$, 导致了不同植被类型下种子 密度的差异 ${ }^{[32]}$. 种子的扩散能力也会受洪水的季节 性和持续时间影响 ${ }^{[33-34]}$, 洲滩湿地植物的种子主要 通过风媒和水媒传播 ${ }^{[35]}$, 有研究表明,在较小空间 尺度内种子扩散能力及进人土壤的数量较为均 匀 ${ }^{[36]}$. 此外, 湿地中多数种子可以通过洪水再分配, 种子漂浮在水面并在水岸边缘聚集,会导致高水位 梯度的种子大量积累 ${ }^{[37]}$.

不同水分条件处理实验中, 湿润条件下萌发物 种以陌上菜、石胡荌、通泉草等湿生植物为主, 沉水 植物因为没有合适的萌发条件而全部缺失, 淹水条 件萌发物种以沉水植物为主, 如金鱼藻、苦草、菹草,

湿生植物因水淹条件抑制了萌发, 导致它们继续休眠, 这一结果验证了淹水状态会影响土壤中种子的萌发 能力 ${ }^{[26]}$. 而湖泊的浅水地带和沿岸地带受水位波动的影响最为显著, 这些区域即使很小的水位变动都会导 致大面积的水体环境与裸露陆地生境之间的转换 ${ }^{[38]}$.

本研究中, 土壤种子库中萌发的物种以一年生草本植物为主. 由于其存活时间较短, 在生活周期内, 可 以产生大量小而轻的种子, 并进人到土壤种子库中 ${ }^{[40]}$. 从低水位的泥沙洲滩区域向高水位的南荻洲滩区 域, 地表植被物种丰富度逐渐增加, 且地表植被与土壤种子库的相似性在长期水淹的泥沙洲滩最低, 而在水 位波动频繁的泥沙一湖草洲滩相似性最高, 这与 Schwab 等的研究结果相似 ${ }^{[41]}$. Capon 等的研究也表明, 在洪 水更频繁的区域, 地表植被与土壤种子库具有更高的相似性 ${ }^{[42]}$. 此外, Touzard 等发现, 土壤种子库与未受干 扰的地表植被相似性较低,地表植被受到干扰后,种子库可以获得一定的萌发空间 ${ }^{[43]}$.

洞庭湖各类型洲滩下, 土壤种子库与地表植被物种组成相似性总体较低, 并且, 地表植被物种丰富度普 遍高于种子库. 洪水会增加种子库的丰度, 但会降低种子库中物种的丰富度和多样性 ${ }^{[44]}$. 已有研究表明,西 洞庭湖洲滩湿地土壤种子库与地表植被物种组成的相似性系数介于 $0.23 \sim 0.41$ 之间 ${ }^{[45]}$. 可能由于洞庭湖湿 地的苔草、曧草、芦苇、南荻等优势种主要依赖营养繁殖来维持种群规模, 种子库中不存在或很少存在这些 物种的种子, 因此极大降低了地表植被与土壤种子库的相似性 ${ }^{[46]}$. 同时, 芦苇和南荻是当地的经济作物, 用 作造纸原料, 在其种子进人土壤种子库前就被收割, 也会导致产生的种子部分无法进人土壤种子库 ${ }^{[19]}$. 种 子库中陌上菜、石胡荌、通泉草等优势种在地表群落中的重要值均接近 0 , 可能是由于上层苔草或曧草群落 盖度过高, 阻隔了阳光, 而这些物种需要处于阳光下才会萌发 ${ }^{[4]}$. 由于湿地植物对洞庭湖特殊水文环境的 适应, 洪水后部分主要伴生种如水田碎米荠 (Cardamine lyrata)、黄鹤菜 (Youngia japonica) 、泥胡菜 (Hemistepta lyrata) 等物种会快速萌发, 仅存在于地表植被, 而在土壤种子库中缺少这些物种. 以上这些原因 可能共同导致了地表植被的物种丰富度高于土壤种子库,且两者相似性较低.

本研究发现水文条件对洲滩湿地植被的更新潜力起着决定性的作用. 水位升高淹没洲滩会抑制种子的 萌发, 水位下降洲滩出露则能够促进种子萌发. 这说明在洲滩湿地保护和恢复过程中, 水位控制是至关重要 的环节, 能对洲滩植被的更新潜力和演替模式产生关键性的影响. 同时, 地表植被与土壤种子库物种丰富度 和相似性的差异表明, 仅依靠土壤种子库进行洲滩湿地植被恢复难以达到理想效果, 一些湿地中常见的植 物如曧草、南荻及部分苔草属植物主要依靠营养繁殖, 将会在恢复过程中缺失, 需要进行人工引种. 为保证 洲滩湿地种子正常萌发, 洞庭湖冬季水位需保持在较低水平, 湖区水文调控及水利枢纽建设之前应考虑其 对洲滩植被的影响. 


\section{4 附录}

附录 I 见电子版 (DOI: 10.18307/2020.0314).

\section{5 参考文献}

[ 1 ] Costanza R, d'Arge R, de Groot R et al. The value of the world's ecosystem services and natural capital. Nature, 1997, 387(6630): 253-260. DOI: 10.1038/387253a0.

[ 2 ] Cui NX, Wu J, Cheng SP et al. Research progress of seed bank for restoration of wetland vegetation. J Lake Sci, 2013,25 (1) : 1-8. DOI: 10.18307/2013.0101. [崔娜欣, 吴娟, 成水平等. 湿地种子库及其植被恢复研究进展. 湖泊科学, $2013,25(1): 1-8$.

[ 3 ] Zedler JB. Progress in wetland restoration ecology. Trends in Ecology \& Evolution, 2000, 15(10) : 402-407. DOI: 10. 1016/s0169-5347(00)01959-5.

[ 4 ] Lai XJ, Jiang JH, Huang Q. Impact of Three Gorges reservoir on water levels in the middle-lower Yangtze River after flood season: Simulation study during 2006-2011. Resources and Environment in the Yangtze Basin, 2014, 23(4) : 475-481. [赖锡军, 姜加虎, 黄群. 三峡对长江中下游干流汛末水位影响—-2006-2011 年实例模拟. 长江流域资源与环 境, 2014, 23(4): 475-481.]

[ 5 ] Zhang QJ, Yu XB, Hu BH. Research on the characteristics of plant communities in the Poyang Nanji Wetlands, China. Resources Science, 2013, 35(1) : 42-49. [张全军, 于秀波, 胡斌华. 鄱阳湖南矶湿地植物群落分布特征研究. 资源 科学, 2013, 35( 1): 42-49.]

[ 6 ] Dong L, Xu LG, Xu JX et al. Effects of soil environmental factors on vegetation distribution in shoaly wetlands typical to Poyang lake. Acta Pedologica Sinica, 2014, 51(3) : 618-626. DOI: 10.11766/trxb201307230347. [董磊, 徐力刚, 许 加星等. 鄱阳湖典型洲滩湿地土壤环境因子对植被分布影响研究. 土壤学报, 2014, 51(3) : 618-626.]

[ 7 ] Leck MA, Parker VT, Simpson RL eds. Ecology of Soil Seed Banks. Academic Press, 1989: 385-444.

[ 8 ] Liu F, Liu H, Xu LX et al. Heterogeneity in the seed bank along the water gradient of the Gahai Lake wetland on the eastern Qinghai-Tibet Plateau. Chinese Science Bulletin, 2013, 58(14)：1332-1339. DOI: 10.1360/972012-1510. [ 刘帆, 刘晖, 徐凌翔等. 青藏高原东部尔海湿地种子库沿水位梯度的分布格局. 科学通报, 2013, 58(14) : 1332-1339.]

[ 9 ] Wolda H. Similarity indices, sample size and diversity. Oecologia, 1981, 50(3) : 296-302. DOI: 10.1007/bf00344966.

[10] Liu GH, Xiao C, Chen SF et al. The role of soil seed bank in wetland restoration and biodiversity conservation in the middle and lower reaches of the Yangtze River. Natural Science Progress, 2007, 17(6) : 741-747. [刘贵华, 肖荗, 陈漱飞 等. 土壤种子库在长江中下游湿地恢复与生物多样性保护中的作用. 自然科学进展, 2007, 17(6) : 741-747.]

[11] Lin YZ, Fu RS eds. Ecology: 2nd Edition. Beijing: Science Press, 2011. [林育真, 付荣恕. 生态学: 第2 版. 北京: 科 学出版社, 2011.]

[12] Li W, Zhang S, Cui L et al. Relationship between distribution of soil seed bank and environmental factors in lakeshore wetlands, Taihu Lake, China. Wetland Science, 2014, 12(6) : 723-732.

[13] Baldwin AH, Derico EF. The seed bank of a restored tidal freshwater marsh in Washington, DC. Urban Ecosystems, 1999, 3(1) : 5-20. DOI: 10.1023/A:1009549117419.

[14] Brown SC. Remnant seed banks and vegetation as predictors of restored marsh vegetation. Canadian Journal of Botany, 1998, 76(4) : 620-629. DOI: 10.1139/cjb-76-4-620.

[15] Kalisz S, McPeek MA. Extinction dynamics, population growth and seed banks. Oecologia, 1993, 95(3) : 314-320. DOI: $10.1007 / \mathrm{bf00320982.}$

[16] Hou ZY, Xie YH, Yu XY et al. Research method, content, and prospect on seed bank of freshwater wetland. Chinese Journal of Ecology, 2008, 27 (8) : 1400-1405. DOI: 10.13292/j.1000-4890.2008.0268. [侯志勇, 谢永宏, 于晓英等. 淡水湿地种子库的研究方法、内容与展望. 生态学杂志, 2008, 27(8) : 1400-1405.]

[17] Middleton B. Hydrochory, seed banks, and regeneration dynamics along the landscape boundaries of a forested wetland. Plant Ecology, 2000, 146(2) : 167-181. DOI: 10.2307/20050891.

[18] Xing F, Wang Y, Xu K et al. Characteristics of soil seed banks of community successional series in marshes in the Sanjiang plain. Wetland Science, 2008, 6(3) : 351-358. [邢福, 王莹, 许坤等. 三江平原沼泽湿地群落演替系列的土壤 
种子库特征. 湿地科学, 2008, 6(3): 351-358.]

[19] Hou ZY, Chen XS, Xie YH et al. Characteristics of soil seed bank and its relationship with aboveground vegetation in Lake Dongting. J Lake Sci, 2012, 24(2) : 287-293. DOI : 10.18307/2012.0218. [侯志勇, 陈心胜, 谢永宏等. 洞庭湖湿地 土壤种子库特征及其与地表植被的相关性. 湖泊科学, 2012, 24(2): 287-293.]

[20 ] Cui LJ, Li W, Zhao XS et al. The relationship between standing vegetation and the soil seed bank along the shores of Lake Taihu, China. Ecological Engineering, 2016, 96: 45-54. DOI: 10.1016/j. ecoleng.2016.03.040.

[21] Jing L, Lyu C, Zhou Y et al. Spatio-temporal characteristics of the expansion of poplar plantation in West Dongting Lake wetland, China. Chinese Journal of Applied Ecology, 2016, 27(7) : 2039-2047. DOI: 10.13287/j.1001-9332.201607. 025. [靖否, 吕偲, 周延等. 西洞庭湖湿地杨树人工林扩张的时空特征. 应用生态学报, 2016, 27( 7 ): 2039-2047.]

[22] Zhu Y, Lv C, Hu HJ et al. Changes in fish community structure in West Dongting Lake after the operation of the Three Gorges dam. J Lake Sci, 2014, 26(6) : 844-852. DOI: 10.18307/2014.0605. [ 朱轶, 吕偲, 胡慧建等. 三峡大坝运行 前后西洞庭湖鱼类群落结构特征变化. 湖泊科学, $2014,26(6)$ : 844-852.]

[23] Jin Z, Lei T. Diversity characteristic of plant communities on beaches of Dongting Lake under different moisture gradients. Wetland Science, 2015, 13(2): 177-183. [靳朝, 雷霆. 水分梯度下洞庭湖洲滩植物群落多样性特征. 湿地科学, $2015, \mathbf{1 3}(2): 177-183$.

[24] Cheng JX, Xu LG, Wang Q et al. Temporal and spatial variations of water level and its driving forces in Lake Dongting over the last three decades. J Lake Sci, 2017, 29(4) : 974-983. DOI: 10.18307/2017.0421. [程俊翔, 徐力刚, 王青等. 洞庭湖近 $30 \mathrm{a}$ 水位时空演变特征及驱动因素分析. 湖泊科学, 2017, 29(4): 974-983.]

[25] Lei T, Middleton BA. Repeated drought alters resistance of seed bank regeneration in baldcypress swamps of North America. Ecosystems, 2018, 21(1) : 190-201. DOI: 10.1007/s10021-017-0143-y.

[26] van der Valk AG, Davis CB. The role of seed banks in the vegetation dynamics of prairie glacial marshes. Ecology, 1978, 59(2) : 322-335. DOI : $10.2307 / 1936377$.

[27] Greulich S, Chevalier R, Villar M. Soil seed banks in the floodplain of a large river: A test of hypotheses on seed bank composition in relation to flooding and established vegetation. Journal of Vegetation Science, 2019, 30(4) : 732-745. DOI: $10.1111 /$ jvs. 12762 .

[28] Bourgeois B, González E, Vanasse A et al. Spatial processes structuring riparian plant communities in agroecosystems: Implications for restoration. Ecological Applications, 2016, 26(7) : 2103-2115. DOI: 10.1890/15-1368.1.

[29] Zhang X, Dong WJ, Shen SK et al. Studies on soil seed bank of lakeside zone: A review. Wetland Science, 2016, 14(1): 97-102. [张雪, 董文婧, 申仕康等. 湖滨带土壤种子库研究进展. 湿地科学, 2016, 14(1): 97-102.]

[30] Hu JY, Xie YH, Tang Y et al. Changes of vegetation distribution in the East Dongting Lake after the operation of the Three Gorges dam, China. Frontiers in Plant Science, 2018, 9: 582. DOI: 10.3389/fpls.2018.00582.

[31] Carthey AJR, Fryirs KA, Ralph TJ et al. How seed traits predict floating times: A biophysical process model for hydrochorous seed transport behaviour in fluvial systems. Freshwater Biology, 2016, 61(1) : 19-31. DOI : 10.1111/fwb.12672.

[32] Reid M, Reid M, Capon S et al. Are flood plain-wetland plant communities determined by seed bank composition or inundation periods? Sediment Dynamics and the Hydromorphology of Fluvial Systems, 2006, 306: 241-248.

[33] Boedeltje G, Bakker JP, Ten Brinke A et al. Dispersal phenology of hydrochorous plants in relation to discharge, seed release time and buoyancy of seeds: The flood pulse concept supported. Journal of Ecology, 2004, 92( 5) : 786-796. DOI: 10.1111/j.0022-0477.2004.00906.x.

[34] Riis T. Dispersal and colonisation of plants in lowland streams: Success rates and bottlenecks. Hydrobiologia, 2008,596 (1) : 341-351. DOI: 10.1007/s10750-007-9107-0.

[35] Howe HF, Smallwood J. Ecology of seed dispersal. Annual Review of Ecology and Systematics, 1982, 13(1) : 201-228. DOI : $10.1146 /$ annurev.es.13.110182.001221.

[36] Nielsen DL, Campbell C, Rees GN et al. Seed bank dynamics in wetland complexes associated with a lowland river. Aquatic Sciences, 2018, 80(2) : 23. DOI: 10.1007/s00027-018-0574-3.

[37] Smith LM, Kadlec JA. The effects of disturbance on marsh seed banks. Canadian Journal of Botany, 1985, 63(12): 2133-2137. DOI: 10.1139/b85-301.

[38] Grelsson G, Nilsson C. Vegetation and seed-bank relationships on a lakeshore. Freshwater Biology, 1991, 26(2) : 199- 
207. DOI: $10.1111 /$ j.1365-2427.1991.tb01729.x.

[39] Chen ZL. Study on plant communities of littoral zone of Three Gorges Reservoir [Dissertation]. Chongqing: Chongqing University, 2011. [陈忠礼. 三峡库区消落带湿地植物群落生态学研究 [ 学位论文]. 重庆: 重庆大学, 2011.]

[40] Liu GH, Li W, Zhou J et al. How does the propagule bank contribute to cyclic vegetation change in a lakeshore marsh with seasonal drawdown? Aquatic Botany, 2006, 84(2) : 137-143. DOI : 10.1016/j.aquabot.2005.08.005.

[41] Schwab A, Kiehl K. Analysis of soil seed bank patterns in an oxbow system of a disconnected floodplain. Ecological Engineering, 2017, 100: 46-55. DOI: 10.1016/j.ecoleng.2016.11.068.

[42] Capon SJ, Brock MA. Flooding, soil seed bank dynamics and vegetation resilience of a hydrologically variable desert floodplain. Freshwater Biology, 2006, 51(2) : 206-223. DOI: 10.1111/j.1365-2427.2005.01484.x.

[43] Touzard B, Amiaud B, Langlois E et al. The relationships between soil seed bank, aboveground vegetation and disturbances in an eutrophic alluvial wetland of Western France. Flora - Morphology, Distribution, Functional Ecology of Plants, 2002, 197 (3) : 175-185. DOI: 10.1078/0367-2530-00029.

[44] Osunkoya OO, Ali S, Nguyen T et al. Soil seed bank dynamics in response to an extreme flood event in a riparian habitat. Ecological Research, 2014, 29(6) : 1115-1129. DOI: 10.1007/s11284-014-1198-2.

[45] Peng LL. Spatial variation of soil seedbank germination in floodplain of West Dongting Lake [Dissertation]. Beijing: Beijing Forestry University, 2019. [彭玲莉. 西洞庭湖洲滩湿地土壤种子库萌发特征空间差异性分析 [ 学位论文]. 北 京: 北京林业大学, 2019.]

[46] Liu QY, Jiang M, Lv XG et al. A review of similarity between soil seed bank and aboveground vegetation in wetlands. Acta Ecologica Sinica, 2014, 34(24) : 7465-7474. DOI: 10.5846/stxb201303120403. [刘庆艳, 姜明, 吕宪国等. 湿地土 壤种子库与地上植被相似性关系研究评述. 生态学报, 2014, 34(24)：7465-7474.]

[47] Amiaud B, Touzard B. The relationships between soil seed bank, aboveground vegetation and disturbances in old embanked marshlands of Western France. Flora - Morphology, Distribution, Functional Ecology of Plants, 2004, 199(1) : 25-35. DOI: 10.1078/0367-2530-00129. 


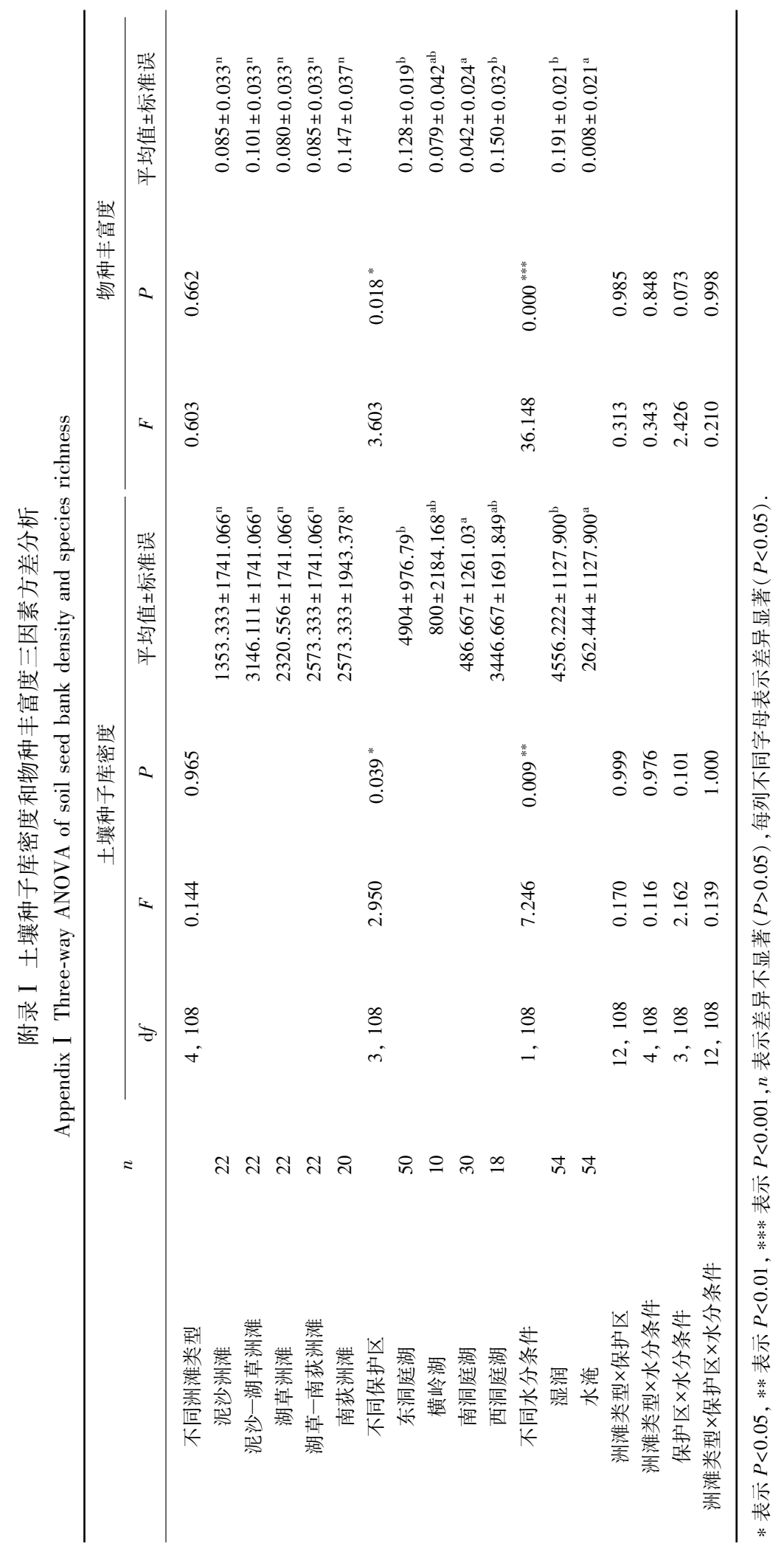

